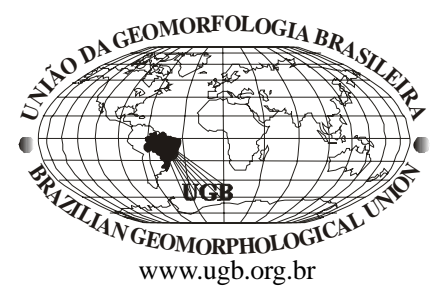

\title{
MORFOTECTÔNICA DA BACIA HIDROGRÁFICA DO RIO BONITO, PETRÓPOLIS, RJ ${ }^{1}$
}

\author{
Laura Delgado Mendes \\ Universidade Federal Rural do Rio de Janeiro - Instituto Multidisciplinar \\ Campus Nova Iguaçu - Av. Prof. Paris, s/nº, Nova Iguaçu, 26221-150 - RJ - Brasil. \\ e-mail: lauraim@ufrrj.br \\ Nelson Ferreira Fernandes \\ Universidade Federal do Rio de Janeiro - Instituto de Geociências \\ Cidade Universitária - Caixa-Postal 68537 - Ilha do Fundão, 21945-970 - RJ - Brasil \\ e-mail: nelsonff@acd.ufrj.br \\ Ambrosina Helena Ferreira Gontijo-Pascutti \\ Universidade do Estado do Rio de Janeiro - Faculdade de Geologia \\ Rua São Francisco Xavier 524, Maracanã, Rio de Janeiro, 20550-900 - RJ - Brasil. \\ e-mail:ahgontijo@uerj.br
}

\begin{abstract}
Resumo
O objetivo deste trabalho é investigar o papel das estruturas subjacentes associadas à evolução tectônica regional e o seu reflexo na geomorfologia, a partir de uma abordagem morfotectônica na bacia do rio Bonito, localizada no extremo norte do município de Petrópolis, Planalto Serrano do Estado do Rio de Janeiro. As estruturas identificadas na área correspondem a falhas e famílias de juntas, que estão relacionadas com as descontinuidades de caráter regional e diretamente associadas ao contexto geológico regional ao qual se inserem, exibindo condições significativamente marcadas pelos processos vinculados à ruptura continental e abertura do Oceano Atlântico, iniciados a partir do Jurássico Superior, especialmente pela reativação de descontinuidades preexistentes. O controle tectônico-estrutural se reflete na compartimentação morfotectônica a partir (a)da integração dos dados estruturais, da análise dos lineamentos da rede de drenagem, que definem trends de lineamentos que correspondem a estruturas identificadas e medidas, (b) do relevo, que apresenta escalonamentos e o desenvolvimento de vales suspensos, e (c) da distribuição espacial da cobertura sedimentar que reproduz a complexidade de feições observadas tanto no contexto local quanto no regional. Dessa maneira, tendo como princípio que a tectônica influencia diretamente a evolução da paisagem, os dados obtidos mostram uma interferência direta das estruturas na compartimentação morfotectônica e na dinâmica e evolução da paisagem da área em estudo.
\end{abstract}

Palavras-Chave: Geomorfologia Tectônica; Morfotectônica; Evolução da Paisagem

${ }^{1}$ Artigo baseado na Dissertação de Mestrado do primeiro autor: “Tectônica, rede de drenagem e sedimentação no Planalto Serrano do Estado do Rio de Janeiro: o caso da bacia do rio Bonito (Petrópolis, RJ)”, defendida em 2004 no Programa de Pós-Graduação em Geografia da Universidade Federal do Rio de Janeiro, com auxílio financeiro da Coordenadoria de Aperfeiçoamento de Pessoal de Nível Superior (CAPES). 
Mendes, L. D.; Fernandes, N. F.; Gontijo-Pascutti, A. H. F.

\begin{abstract}
The aim of the present work was to investigate the role played by basement structure associated with the regional tectonic evolution and its effects in geomorphological structures from the morphotectonic approach in Bonito river basin, located in far north of the Petropolis city, Serrano Plateau of the Rio de Janeiro State. The structures in the study area correspond to faults and families of lineaments and are related with the regional discontinuities. Such structures are directly associated to the regional geologic context, and reflect the consequences from the continental rupture and the Atlantic Ocean opening, initiated from the Upper Jurassic, especially by the reactivation of preexisting discontinuities. The tectonic-structural control reflects morphotectonic compartments from (a) the lineaments and drainage network, which defines trends of lineaments, (b) the relief and (c) the spatial distribution of sedimentary cover. The results show the interference of the structures, in the morphotectonic units and also in the landscape evolution of the study area.
\end{abstract}

Keywords: Tectonic Geomorphology; Morphotectonic; Landscape Evolution

\section{Introdução}

Diversos estudos buscam compreender a relação entre a evolução do relevo e o condicionamento tectônico, tanto em domínios de bordas de placa ativas como em domínios intraplaca (Ollier, 1981; Wallace, 1986; Summerfield, 1987; Hasui, 1990; Stewart \& Hancock, 1994; Keller \& Pinter, 1996, Burbank \& Anderson, 2001, entre outros).

No Brasil, as pesquisas desenvolvidas que procuram reconstituir os processos de evolução do relevo e de deposição associados à evolução mesozóico-cenozóica têm mostrado que tais processos envolveram movimentos tectônicos relacionados à abertura do Atlântico Sul e a outros movimentos, mais modernos, ligados à rotação da placa SulAmericana para oeste (Hasui et al., 1998).

Freitas (1951a; 1951b; 1956), Ruellan (1944), Almeida (1967) e outros já se referiam a movimentos recentes na Plataforma Brasileira desde meados do século passado, mas somente a partir da década de 80 surgiram os primeiros trabalhos sobre a atividade neotectônica na Região Sudeste (Riccomini, 1989; Saadi, 1990, 1993; Hasui, 1990; Hasui \& Costa, 1996; Hasui et al., 1998; Santos, 1999; Gontijo et al., 2002a; Gontijo, 1999; Ferrari, 2001; Hiruma et al., 2001, entre outros), impulsionados especialmente pela crescente preocupação quanto à estabilidade geológica das áreas na medida em que são observados um crescimento urbanoindustrial significativo e a necessidade de implantação de obras de engenharia de grande porte. E ressalta-se, inclusive, a execução de estudos de sismicidade (Hasui et al., 1982; Assumpção, 1989) e da análise de traços de fissão (Gallagher et al., 1995; Hackspacher et al., 1999) que indicam soerguimentos e erosão gradual a partir do Cretáceo.

É importante destacar que os esforços a que as regiões intraplaca estão submetidas ocorrem de maneira diferenciada quando comparados com o comportamento de áreas próximas às margens tectonicamente ativas, onde os reflexos dos pulsos tectônicos relacionados ao contato entre as placas são observados de maneira mais direta (Salvador \& Riccomini, 1995). Com o afastamento dessas zonas ativas, os esforços na crosta são influenciados por fatores locais, como proximidade com a margem continental e a carga de sedimentos acumulada, além de descontinuidades pré-existentes que são reativadas (op.cit.). Essas estruturas do embasamento reativadas associam-se a zonas de cisalhamento brasilianas, com orientação ENE, geradas por um evento tectônico póscolisional (Heilbron et al., 2000) e que se comportam como zonas de fraqueza preferencial (Ferrari, 2001).

Destaca-se, dessa forma, a importância desta tectônica na evolução geológico-geomorfológica da Região Sudeste, no contexto do Sistema de Riftes da Serra do Mar (Almeida, 1976) ou Riftes Continentais do Sudeste do Brasil (Riccomini, 1989) onde os processos de denudação acabam se tornando mais atuantes (Carmo, 2004), mascarando as feições associadas a movimentações tectônicas. Considera-se ainda a necessidade de caracterização sobre a configuração morfoestrutural e morfotectônica com vistas a uma melhor compreensão sobre a evolução do relevo e as suas relações sob o aspecto de distribuição e gestão de recursos minerais e hídricos e de uso e ocupação do solo.

Os estudos desenvolvidos na Região Sudeste apontam relações entre a história evolutiva mesozóico-cenozóica e a dinâmica dos processos de morfogênese (Riccomini, 1989; Riccomini et al.,1989; Mello et al., 1989, 1995; Mello, 1992; Melo et al., 1985; Dantas et al., 1994; Carmo, 1996; Saadi, 1990, 1993; Saadi \& Valadão, 1990; Salvador \& Riccomini, 1995; Almeida \& Carneiro, 1998; Hasui, 1990; Hasui et al., 1998; Costa et al., 1998; Gontijo, 1999; entre outros) e, especialmente no que se refere ao Planalto Serrano do Estado 
do Rio de Janeiro, é destacada a sua importância sob ponto de vista das feições morfológicas, tectônicas, estruturais, sedimentares e magmáticas que exibe, associadas a tal evolução.

Nesse contexto, o artigo representa uma tentativa de contribuição ao entendimento sobre o papel das estruturas subjacentes associadas à evolução geológica (tectônica) regional e o seu reflexo na geomorfologia, a partir da abordagem morfotectônica.

\section{2. Área de estudo}

A área de estudo é a bacia hidrográfica do rio Bonito (sub-bacia do rio Piabanha), localizada no extremo norte do município de Petrópolis (Distrito de Posse), Estado do Rio de Janeiro, correspondendo a uma área aproximada de $60 \mathrm{~km}^{2}$, situada na zona de degraus da Serra dos Órgãos (Silva, 2002) (Figura 1).

Litologicamente a área localiza-se no Terreno Oriental da Faixa Ribeira (Heilbron et al., 1999), definido pela Zona de Cisalhamento Arcádia-Areal, que representa o Contato Tectônico Central ou Central Tectonic Boundary (Almeida, 2000). A Faixa Ribeira é resultado de uma colisão oblíqua entre dois blocos continentais entre o Neoproterozóico e o Ordoviciano (Brasiliano), que empilhou terrenos com características estruturais distintas (Almeida, 2000), representada pelo Domínio Rio Negro, caracterizado pelos ortognaisses do Complexo Rio Negro e granitóides Serra dos Órgãos, diques mesozóicos e sedimentos quaternários (op.cit.).

A bacia do rio Bonito está associada aos granitóides Serra dos Órgãos, com ocorrência do Complexo Rio Negro apenas na área de confluência com o rio Preto, o qual está encaixado na Zona de Cisalhamento Rio Preto.

Os lineamentos identificados por Almeida (2000) apresentam orientação preferencial para NNE, com orientações variando de NNW à NNE, correspondentes na área de estudo aos eixos das drenagens principais. Esta orientação é definida pela estruturação pré-Cambriana, associada às zonas de cisalhamento que foram reativadas pela tectônica extensional Waldeniana (Almeida, 1967) ou Sul-Atlantiana (Schobbenhaus \& Campos, 1984), responsável por fenômenos de deformação continental rúptil que incidiram na Região Sudeste a partir do Triássico até o Paleógeno e que culminaram com a ruptura e separação entre a América do Sul e a África, desenvolvimento de margem continental passiva e abertura do Oceano Atlântico (Morales \& Hasui, 2001). Esse tectonismo foi responsável pela geração de falhas e lineamentos de direção NE-SW, E-W, NW e N-S, com movimentação de blocos sob regime tectônico distensivo, gerando soerguimentos e abatimentos de blocos por falhas (horsts e grábens), criando grandes traços do relevo, como a Serra do Mar, altos e depressões (arcos e bacias) e possibilitou derrames vulcânicos, intrusões e sedimentação (op.cit.).

Além desta reativação, ocorre outra mais nova, correspondente à neotectônica, responsável pela geração de falhamentos cenozóicos e pelo condicionamento da evolução morfodinâmica da paisagem do sudeste (Hasui, 1990).

Baseado em Silva (2002) a área localiza-se no Domínio Morfoestrutural do Planalto Atlântico, na Região do Planalto e Escarpas da Serra dos Órgãos, posicionada entre as Unidades Geomorfológicas de colinas/morros e maciços costeiros e Alinhamento de cristas Paraíba do Sul, que compreende continuamente uma área de Itaguaí, a sul do Estado, até o município de Campos dos Goitacazes, a norte. A bacia do rio Bonito situa-se no compartimento Degraus e/ou serras elevados e/ou escarpados (op.cit.).

\section{Metodologia}

Numa abordagem multidisciplinar foram utilizados procedimentos e técnicas da Geologia Estrutural e Tectônica e da Geomorfologia.

O material cartográfico que serviu de apoio para a pesquisa constitui-se por cartas topográficas na escala de 1:50 000, folhas Três Rios, Anta, Teresópolis e Itaipava (IBGE) e na escala de 1:10 000 (Prefeitura Municipal de Petrópolis), assim como bases geológicas compiladas do Mapa Tectônico da Faixa Ribeira Central (FGEL-UERJ-TEKTOS, inédito), cedidas pelo TEKTOS-UERJ (Grupo de Pesquisa em Geotectônica da Faculdade de Geologia da Universidade do Estado do Rio de Janeiro).

A compartimentação morfotectônica foi elaborada a partir de metodologia adaptada e desenvolvida para regiões de ambiente tectônico intraplaca pelo grupo de estudos neotectônicos da UNESP - Universidade Estadual Paulista (Hasui \& Costa, 1996; Hasui et al., 1998; Borges et al., 1998; Gontijo, 1999; Morales \& Hasui, 2001), assim como de LIU (1987) e baseou-se na análise dos dados estruturais, identificação de trends de lineamentos da rede de drenagem e relevo, desnivelamentos topográficos, anomalias na rede de drenagem e mapeamento de áreas de sedimentação.

A análise de assimetria da bacia por basculamento de blocos devido a causas tectônicas, que utiliza o Fator de Simetria Topográfica transversa (FSTT) (Cox, 1994; Keller \& Pinter, 1996) foi empregada para avaliar o comportamento do rio Bonito e a influência das estruturas subjacentes ao longo de todo o seu curso. A análise é feita em diferentes segmentos do vale e indica a migração preferencial do canal associada a basculamentos, onde são considerados os seguintes índices: $\mathrm{T}=\mathrm{Da} / \mathrm{Dd}$, onde: $\mathrm{T}=$ Fator de Simetria Topográfica Transversa; Da = distância entre a linha média da bacia de drenagem e a linha média do cinturão do meandro ativo; e Dd = distância entre a linha média da bacia e o divisor da bacia de 
Mendes, L. D.; Fernandes, N. F.; Gontijo-Pascutti, A. H. F.

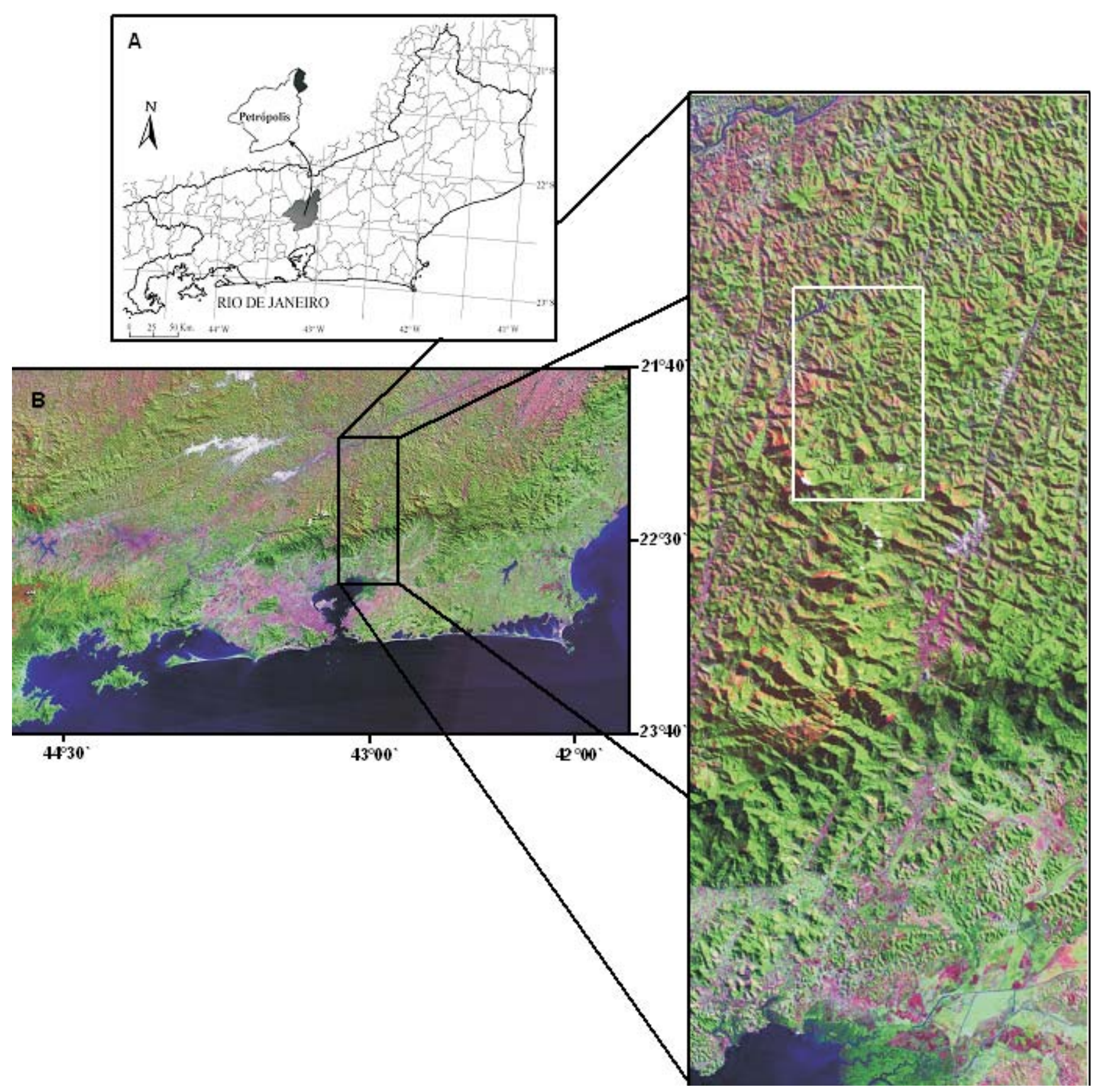

Figura 1 -A) Localização da área de estudo, com destaque para a bacia do rio Bonito no extremo norte do município de Petrópolis, estado do Rio de Janeiro. B) Imagem de satélite Landsat abrangendo o estado do Rio de Janeiro e áreas adjacentes. Em destaque a localização da bacia hidrográfica do rio Bonito.

drenagem. Segundo esta técnica, valores próximos ou iguais a zero (0) indicam simetria e valores próximos ou iguais a um (1) apontam a assimetria e a uma maior influência da tectônica.

Os lineamentos da rede de drenagem foram compilados de Mendes (2001). No programa AUTO CAD, cada direção foi digitalizada em layer distinto, permitindo observar seu padrão, distribuição espacial das orientações, de forma a facilitar a análise qualitativa e quantitativa dos lineamentos. Posteriormente foram gerados diagramas de rosetas na rotina roseta.lisp., sendo produzidos cinco mapas de lineamentos, um deles exibindo o conjunto de orientações (SW-NE, SENW, N-S e E-W).

Os perfis longitudinais foram traçados para o canal principal da bacia e para os principais afluentes do rio bonito, 
totalizando sete (07) perfis longitudinais para a avaliação do comportamento dos rios e condições de equilíbrio fluvial.

Foram traçados cinco (05) perfis topográficos em varredura, baseados na metodologia de MEIS et al. (1982) a partir das cartas topográficas na escala 1:10 000, sendo um deles longitudinal ao rio principal e os outros transversais ao mesmo, correspondendo a uma área de $3 \mathrm{Km}$ de largura e de comprimento variável. Os dados obtidos, correspondentes às coordenadas $\mathrm{X}$ e $\mathrm{Y}$, além dos valores associados aos pontos cotados (Z), foram plotados em gráfico no programa KaleidaGraph.

A seleção das áreas para os traçados dos perfis em varredura considerou os mesmos critérios utilizados para os perfis longitudinais dos canais, ou seja, a observação do comportamento das áreas a partir do traçado longitudinal da bacia, assim como transversal, com o propósito de integrar as observações quanto ao comportamento longitudinal dos eixos dos canais e a configuração do relevo nas áreas em que estão inseridos.

O Modelo Digital de Elevação (MDE) foi gerado com os programas Arc Info e Arc View. O objetivo da sua utilização no desenvolvimento do trabalho foi apresentar a utilização de informações extraídas de cartas topográficas, constituindose ferramenta para a visualização da morfologia e sua relação com a influência de condições morfoestruturais.

Com o suporte de material cartográfico pré-existente e produzido e procedimentos e técnicas da Geologia Estrutural e Tectônica foram observados afloramentos e reconhecidas estruturas (medidas de foliação, planos de falhas, estrias, indicadores cinemáticos, fraturas, diques), sendo de fundamental importância em campo a observação da relação existente entre as estruturas identificadas e mapeadas com a geomorfologia da área, assim como com o quadro geomorfológico regional.

Os dados obtidos em campo em 25 pontos amostrados e totalizando 309 estruturas foram tratados segundo os conceitos de Geologia estrututural (Arthaud, 1969; Angelier \& Mechler, 1977), com a utilização dos programas STEREONET e TECTONICS FP (versão Demo).

Após a integração e análise dos resultados obtidos foram definidos e traçados em Modelo Digital de Elevação (MDE), os cinco (05) compartimentos morfotectônicos da bacia hidrográfica do rio Bonito.

\section{Resultados e discussão}

\subsection{Compartimentação Morfotectônica}

Os principais elementos que caracterizam a compartimentação morfotectônica da área (Figura 2) correspondem: a) a configuração e dinâmica da rede de drenagem, sobretudo na caracterização dos feixes (trends) de lineamentos dos canais fluviais (Figura 3) e a análise de anomalias em condições de assimetria, retilinidade, presença de cotovelos, inflexões, alinhamento de confluências e até mesmo condições de captura de drenagem, tanto na área da bacia quanto no seu entorno (Figura 4).

A rede de drenagem, por ser altamente sensível à transmissão dos inputs desencadeadores de mudanças ambientais (Thomas \& Allison, 1993), torna-se o segmento da paisagem mais vulnerável a qualquer tipo de deformação, em escala temporal que pode variar entre alguns milhões a milhares de anos e séculos a décadas. Assim, seu entendimento é de extrema importância para todos os estudos que envolvem a análise do meio físico e nas abordagens morfotectônicas e neotectônicas constitui uma das mais importantes ferramentas devido às suas respostas imediatas às reativações tectônicas, quer em domínios de bordas de placas como intraplaca.

A geração de anomalias observadas na rede de drenagem e no relevo é relacionada por Gontijo (1999) a fatores de origem tectônica, como basculamento de blocos, soerguimentos e abatimentos de áreas ao longo de falhamentos, sendo responsáveis também pela reestruturação dos processos de erosão e sedimentação. Tais anomalias refletem a importante relação entre a rede de drenagem da área e o contexto tectônico e estrutural ao qual se inserem e podem ser interpretadas como um estágio de reorganização da rede de drenagem e ao seu ajuste às atuais condições estruturais do embasamento resultantes das reativações de estruturas pretéritas).

b) a distribuição espacial das coberturas sedimentares fluviais e de encostas (Figura 5), que refletem a influência das estruturas na geração de áreas onde os processos erosivos e deposicionais atuam mais efetivamente e que apresenta-se fortemente influenciada à condição de assimetria da bacia.

Tal condição foi evidenciada pela análise de assimetria da bacia por basculamento de blocos devido a causas tectônicas, com a aplicação do Fator de Simetria Topográfica Transversa (FSTT) (Cox, 1994; Keller \& Pinter, 1996) (Figura 6). Os valores obtidos para a bacia do rio Bonito indicam um basculamento intermediário, com a ocorrência de valores mais elevados, ou mais anômalos, em áreas onde há coincidências com trends de lineamentos E-W (Figura 3) e que correspondem à imposição de estruturas identificadas e medidas. Nestas áreas ocorrem feições que indicam anomalias na rede de drenagem, como deflexões de canais fluviais evidenciadas por curvas anômalas (Figura 4).

O basculamento da bacia para NW permite evidenciar a diferencial configuração da mesma quando analisados os canais das margens esquerda e direita do rio bonito. Ressal- 
Mendes, L. D.; Fernandes, N. F.; Gontijo-Pascutti, A. H. F.

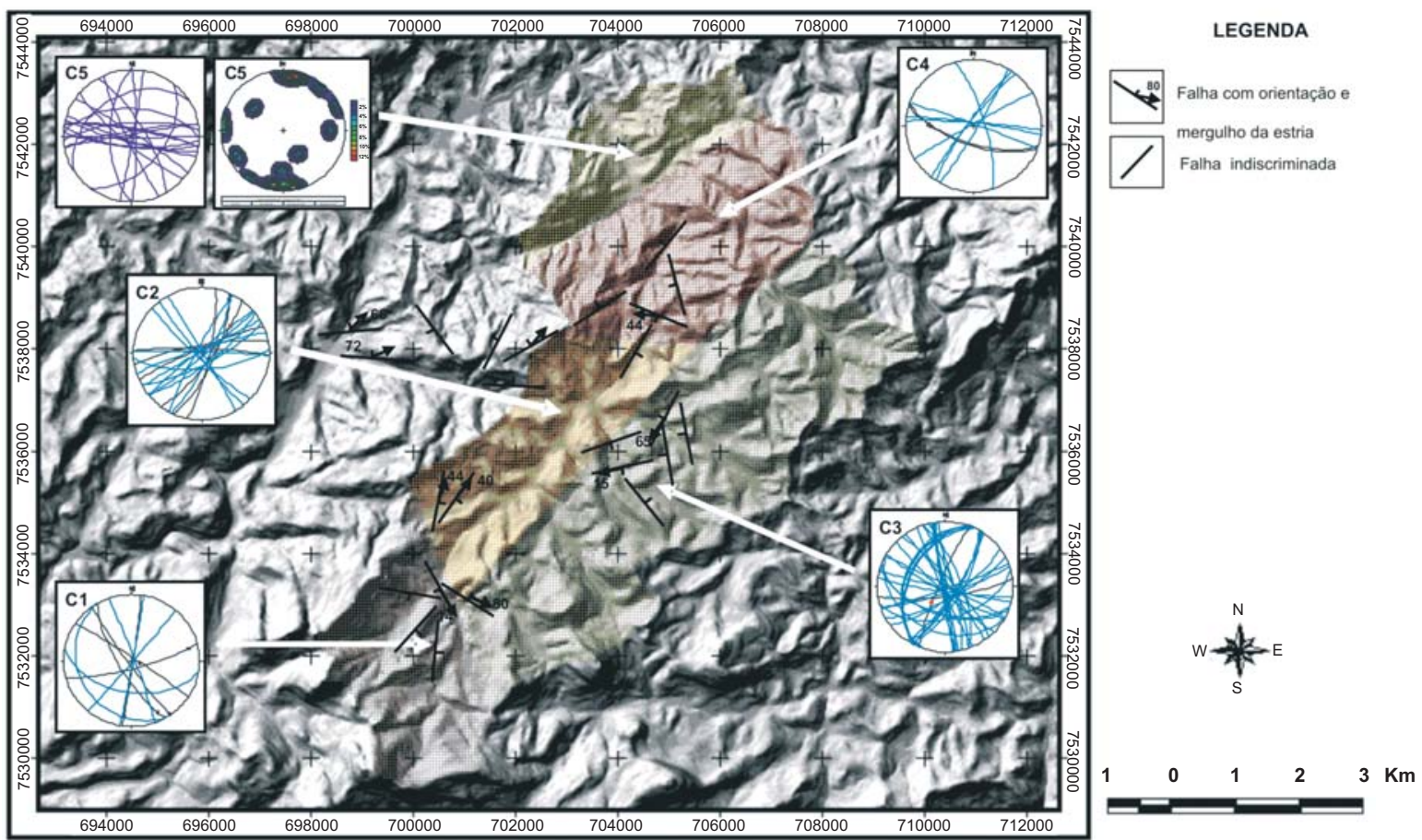

Figura 2 - Compartimentação morfotectônica com principais planos de falhas (com orientação e mergulho das estrias) e projeções estereográficas para os planos de falhas dos compartimentos C1, C2 e C3 e C4 e para as juntas do compartimento C5. Nos diagramas, estão exibidas as falhas normais (pontos em vermelho), sinistrais (pontos em verde), dextrais (pontos em azul claro) e indefinidas (pontos em azul). As linhas ciclográficas em azul correspondem aos planos de falhas medidos sem indicadores.

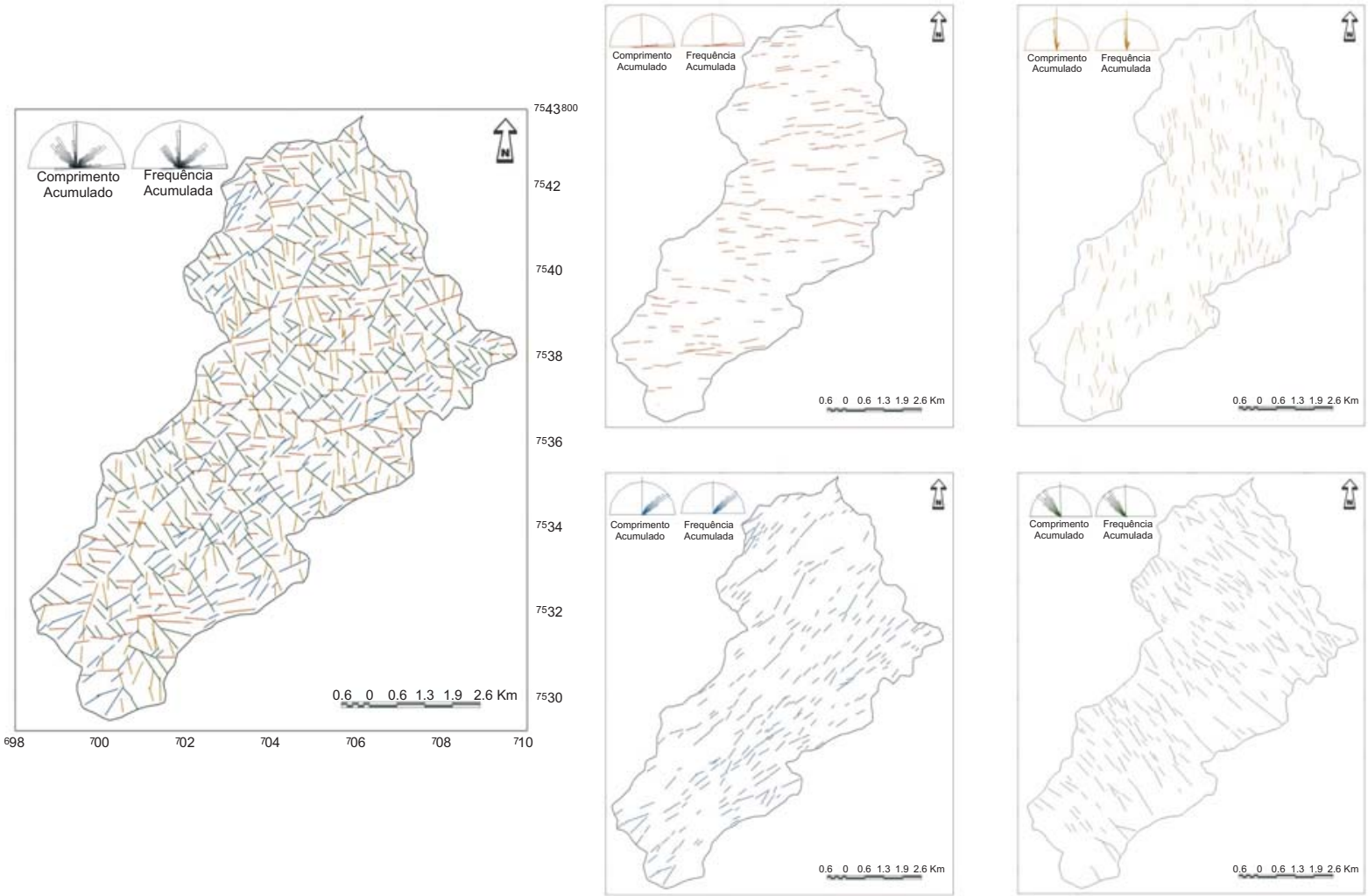

Figura 3 - Orientação dos lineamentos da rede de drenagem. Em (A), visualização de todos os lineamentos, modificado de MENDES (2001); em $B, C, D$ e E, observação das orientações $E-W, N-S, S W-N E$ e SE-NW, respectivamente. 

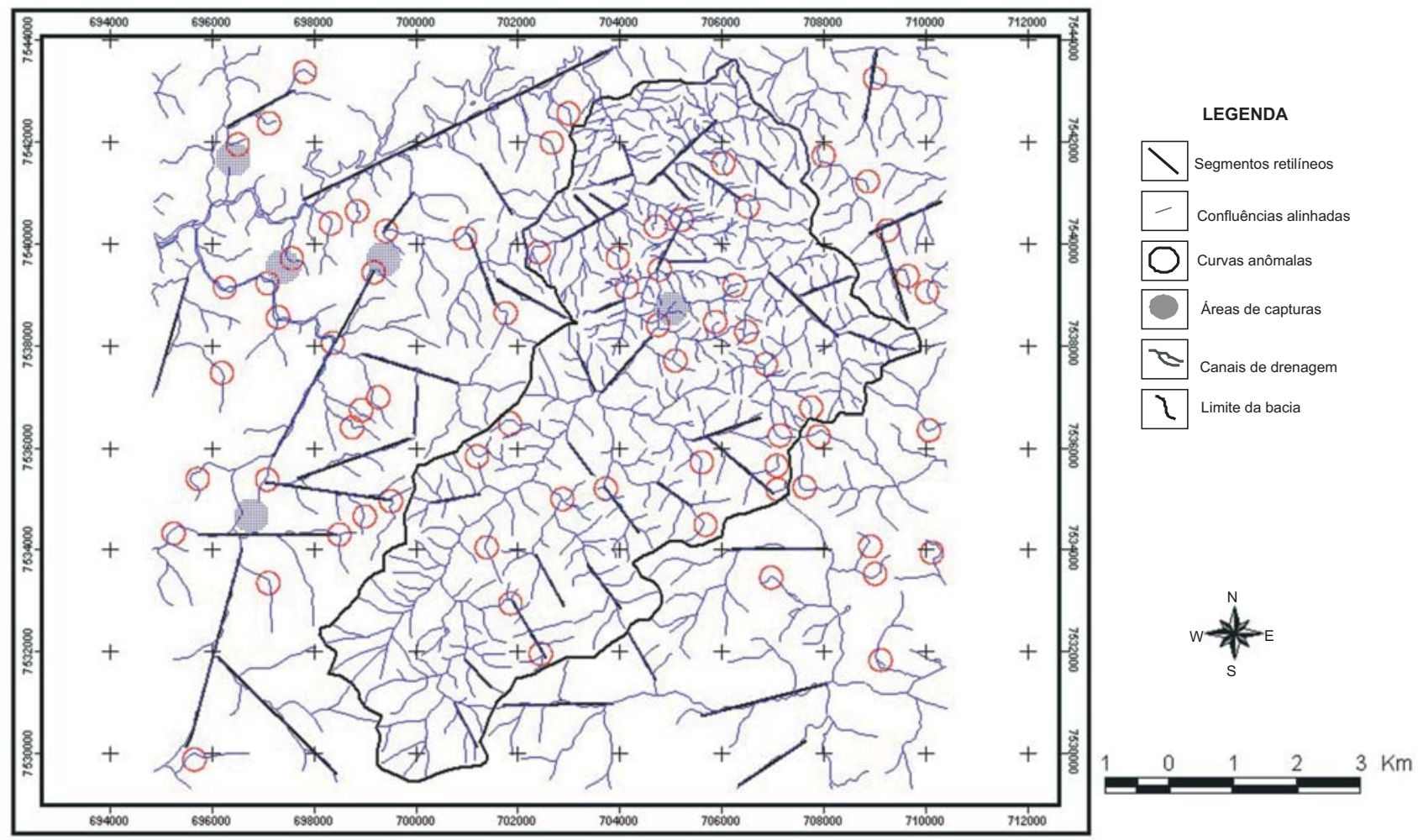

Figura 4 - Mapa de drenagem da bacia do rio Bonito e entorno com anomalias

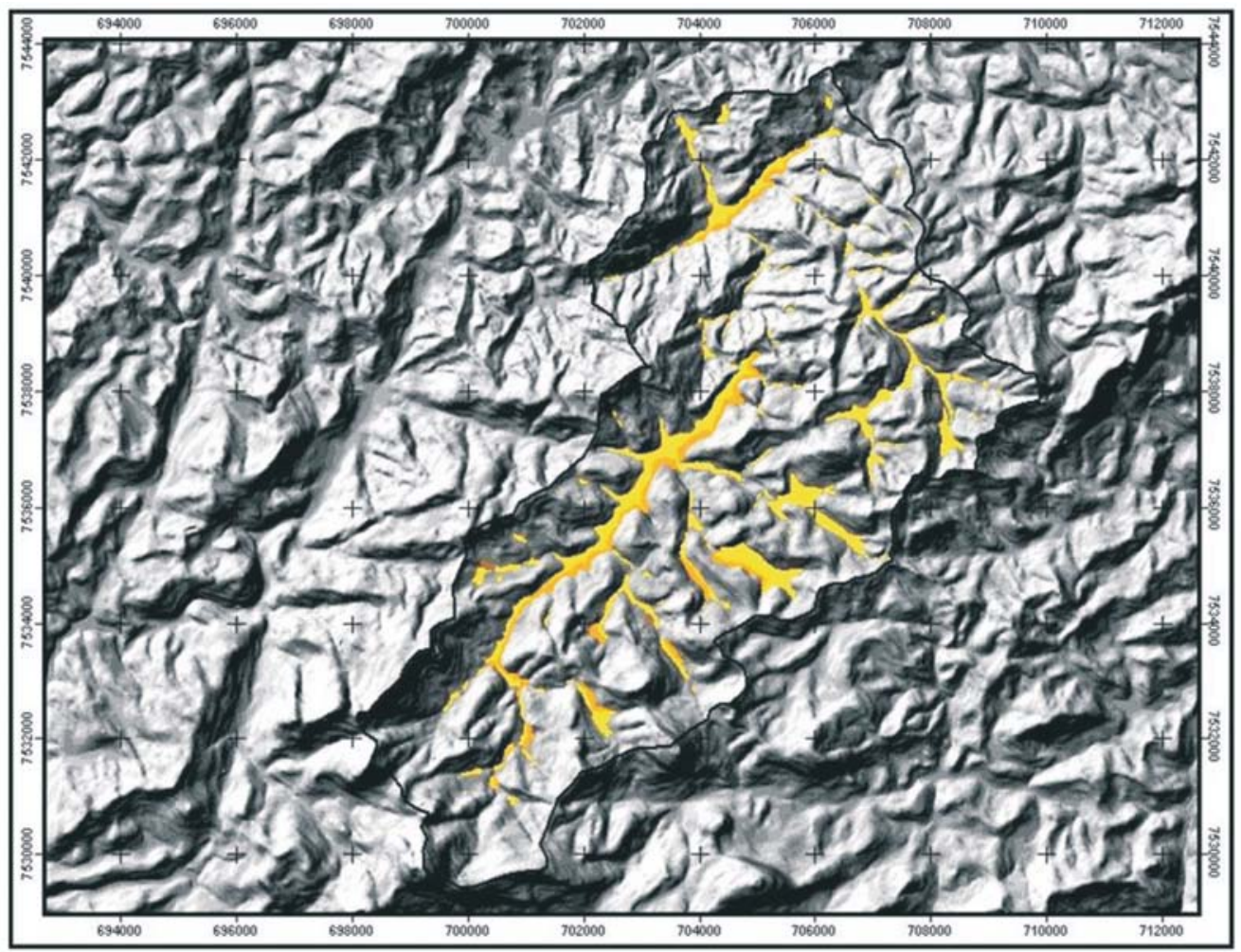

LEGENDA

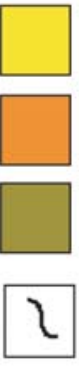

Depósitos aluviais

Depósitos coluviais

Depósitos diferenciados

2 Limite da bacia

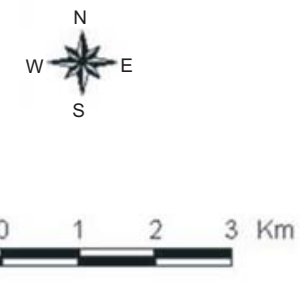

Figura 5-Mapa de coberturas sedimentares da bacia do rio Bonito 


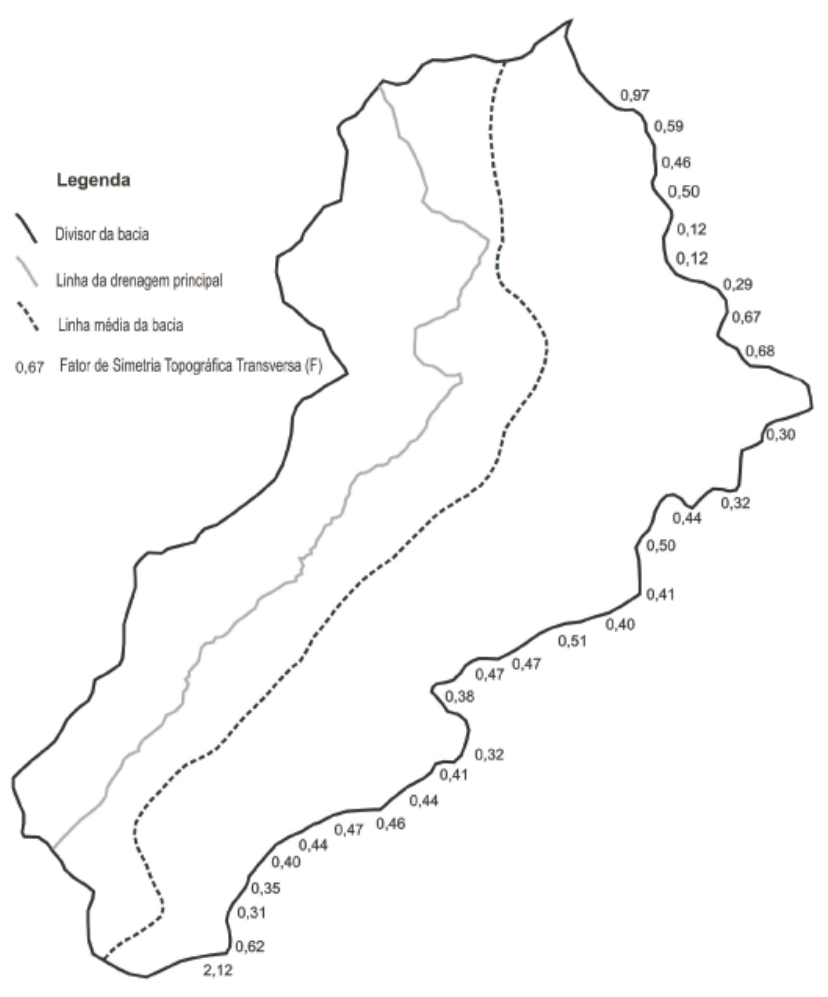

Figura 6 - Análise do basculamento da bacia a partir do Fator de Simetria Topográfica Transversa (FSTT).

ta-se a influência na direção do fluxo dos canais da estrutura subjacente, como a foliação que, mesmo fraca, apresenta caimento para NW, coincidente com o padrão de escalonamento por falhas normais/oblíquas que podem aproveitar e/ou truncar a foliação.

São significativamente mais extensos os canais da margem direita, e que seguem orientação SE-NW, associados às principais drenagens afluentes do rio Bonito, como se observa no Mapa de drenagem com as anomalias (Figura 4). Tais canais apresentam os maiores escalonamentos e zonas de sedimentação alveolar, condição corroborada pela expressiva ocorrência das coberturas coluviais associadas a fluxos de massa lentos, sobretudo na margem direita do rio Bonito (Figura 5).

Ao propor um quadro das relações entre os condicionantes neotectônicos do relevo e a distribuição de formas erosivas e deposicionais, Ferreira (2001) apresenta a manisfestação da atividade tectônica na distribuição de compartimentos morfoestruturais, também condicionados por reativação de descontinuidades pré-existentes, que configuram blocos soerguidos e abatidos, na preservação de sedimentos terciários e quaternários, na reorganização da rede de drenagem, com identificação de feições de anomalias de dre- nagem. O autor ainda chama a atenção para a ocorrência de vales suspensos alinhados, orientação de cinturões meândricos abandonados, retenção de sedimentos, além do desenvolvimento de degraus no perfil longitudinal dos rios, que registram momentos episódicos de atividade tectônica (op. cit), como também pode ser observado na área pesquisada.

c) o mapeamento das estruturas (Figura 2) e o controle das mesmas na dinâmica da rede drenagem e assim, na evolução do relevo, já que a drenagem é o principal agente morfodinâmico ou modelador da paisagem.

Com relação aos dados estruturais apresentados na Figura 2, as foliações de médio a baixo ângulo orientam-se segundo NE e ENE; as fraturas no embasamento, verticais e subverticais, para N-S, N10-20W, NW-SE, N70-80W, NE-SW, E-W, N10-20E e N70E; e nos diques segundo N10-45E, N20W e N40W. As falhas mapeadas no embasamento possuem caráter normal/oblíquo e transcorrente dextral ou sinistral com direções N10-20E, N40E, N70-80E, N40W, N70W e E-W (para mais detalhes ver Mendes, 2004).

Os compartimentos são delimitados por estruturas NE, SW, N-S e E-W e possuem escalonamento tanto paralelo ao vale principal NE-SW, no alto e médio curso, quanto perpendicular, controlado por direções NW e E-W. Revelam nítido controle na morfologia da bacia, no padrão da drenagem, na tipologia dos perfis longitudinais dos canais (Figura 7) e perfis de relevo (Figura 8) e, portanto, nas zonas de erosão e de sedimentação (Figura 5).

A relação entre essas direções com a dissecação da paisagem atual é destacada por vários autores no Planalto Atlântico, como Gontijo (1999), Santos (1999), Neves (1999), que apontam que as principais zonas de dissecação atual da paisagem possuem direções preferenciais NW-SE, de acordo com o regime neotectônico definido por eles.

Nas adjacências foram identificadas estruturas com tais orientações associadas à tectônica mesozóico-cenozóica, com a mesma relação entre a reologia do embasamento, o condicionamento da rede de drenagem e as características e dinâmicas dos processos morfogenéticos (Gontijo et al., 2000; Gontijo et al., 2002b, Cravinho et al., 2003, Melo et al., 2003, entre outros).

\subsubsection{Compartimento C1}

O compartimento C1 (Figura 2) corresponde às cabeceiras da bacia, sendo caracterizado pela presença de feixes de lineamentos de drenagem e de relevo com orientação NESW e NW-SE, além de feixes E-W que o limitam a sul (Figura 3). A orientação do limite sul do compartimento segundo a direção NW-SE corresponde à orientação de uma falha de caráter normal identificada, importante no direcionamento da drenagem, principalmente orientando as confluências dos canais. A presença de falhas sinistrais com orientação N-S e 
Morfotectônica da bacia hidrográfica do rio Bonito, Petrópolis, RJ
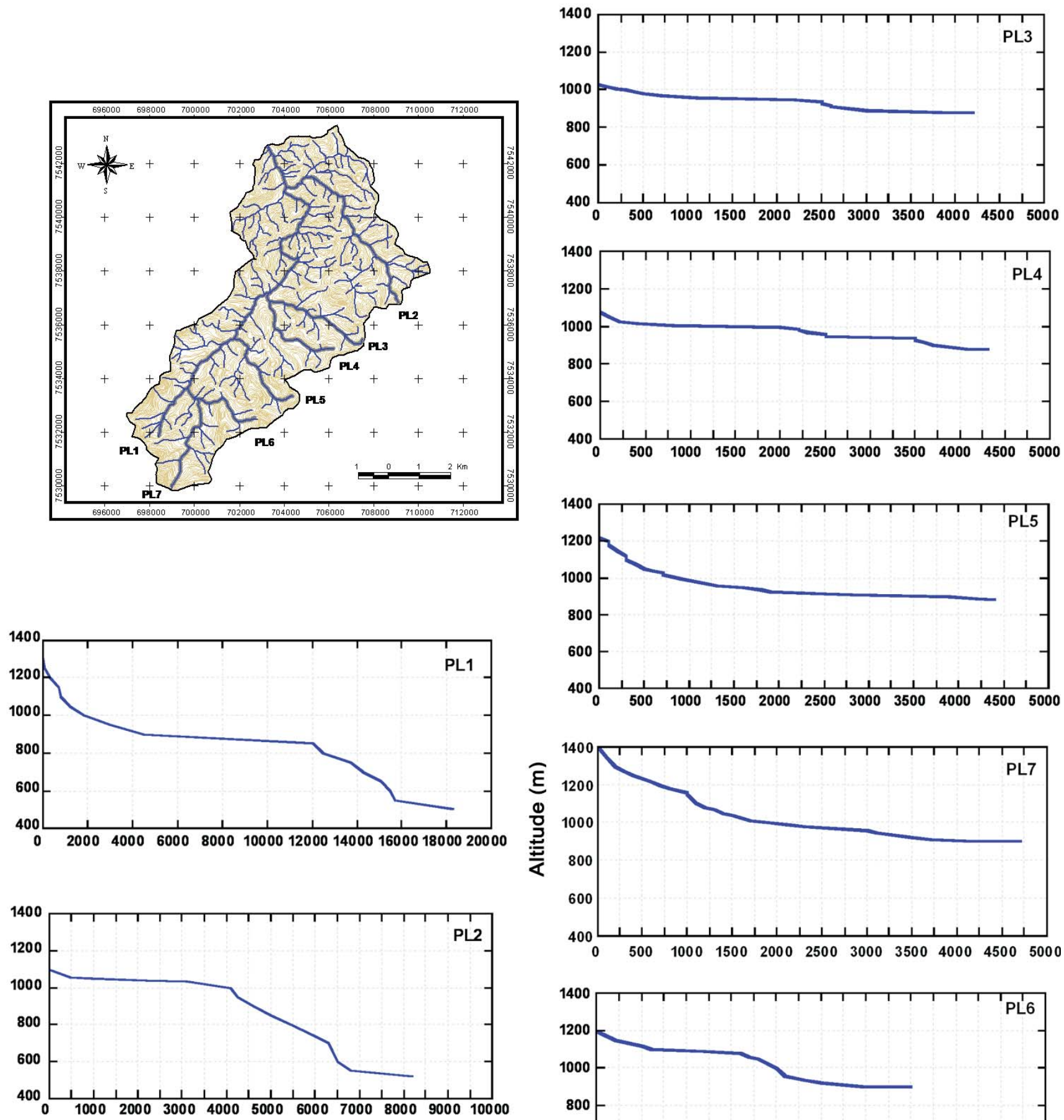

Distância (m)
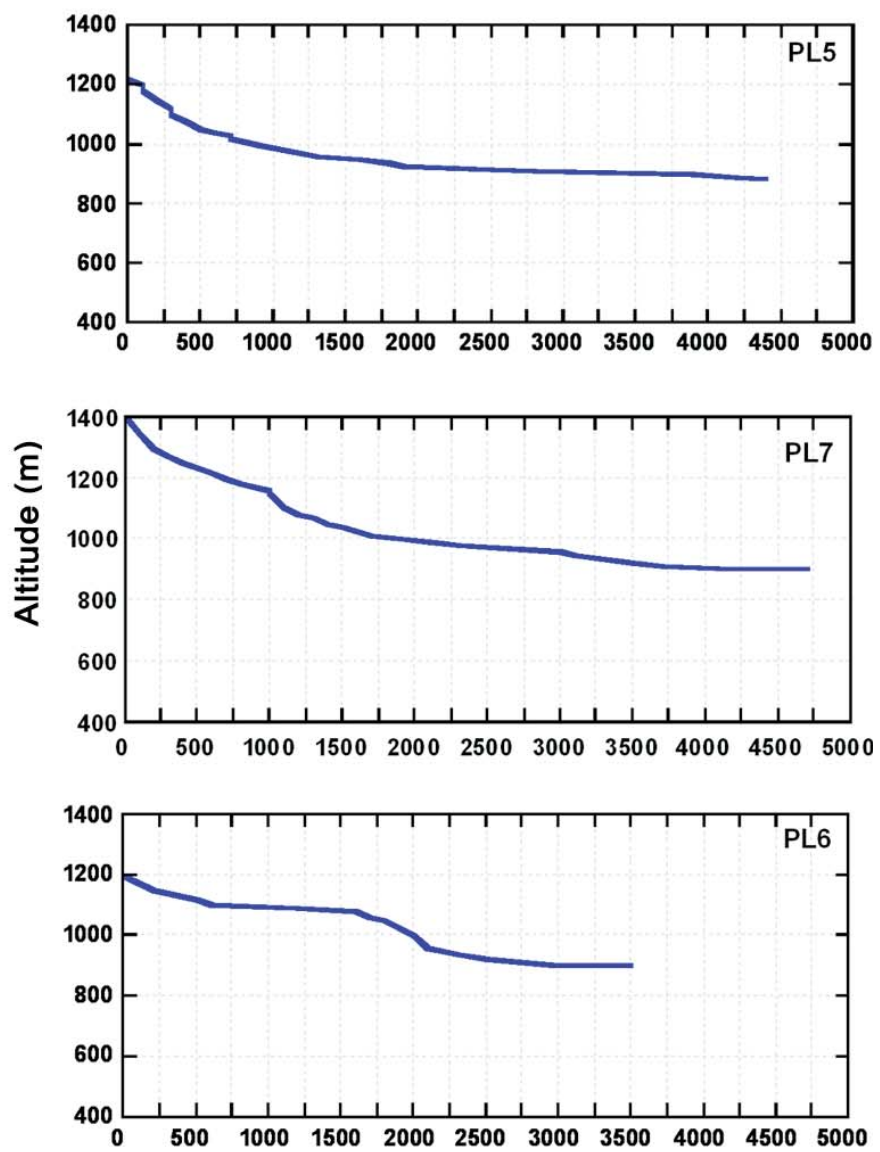

Figura 7 - Perfis longitudinais PL1, PL2, PL3, PL4, PL5, PL6 e PL7 e seus respectivos traçados. 
E80W também assumem importante influência no controle da rede de drenagem nesse compartimento.

\subsubsection{Compartimento C2}

O compartimento C2 (Figura 2) representa uma área de relevo negativo, sendo expressiva a cobertura sedimentar no eixo do canal principal da bacia (Figura 5). Predominam as estruturas NE-SW, com falhas normais, responsáveis pela geração do escalonamento observado na bacia, que promove o desenvolvimento dos vales suspensos no compartimento C3.

Falhas com caráter normal com orientação E-W também são identificadas, variando entre E70W e E80W, onde ocorre um espraiamento da cobertura sedimentar em direção aos vales afluentes, condicionado pela barreira existente para a sedimentação representada pelo alto topográfico representado pelo compartimento C4.

Os processos de sedimentação de depósitos coluviais e aluviais resultaram, de acordo com Riccomini (1989), da estabilidade tectônica atribuída ao Pleistoceno Superior, como conseqüência da erosão dos altos estruturais formados na passagem Oligoceno-Mioceno, período de compressão NE e extensão NW. Ainda de acordo com o autor, outras soleiras foram geradas após essa sedimentação, mas por um regime transcorrente E-W, definindo a atual distribuição dos sedimentos.

As áreas desniveladas em relação ao canal principal da bacia, além de contribuírem com um aporte sedimentar para esse compartimento, apresentam um controle da sedimentação em determinados trechos, associados à ocorrência de knickpoints, promovidos pelo controle estrutural e que definem o compartimento C3, que também atuam no desenvolvimento de coberturas pedológicas diferenciadas espacialmente (Mafra et al., 1999; Mendes, 2001; Mendes et al., 2002).

\subsubsection{Compartimento C3}

No compartimento C3 (Figura 2) são exibidos vales suspensos, alinhados e perpendiculares ao canal principal, segundo estruturas NW-SE, com caráter normal, que promovem o escalonamento da bacia e a formação de vales suspensos alinhados com extensas planícies aluvionares, identificados nos perfis longitudinais e perfis de relevo em varredura (Figuras 7 e 8).

A presença de anomalias na rede de drenagem nesse compartimento está relacionada aos eixos das principais drenagens afluentes do rio Bonito, com orientação NW-SE, que truncam com estruturas orientadas NE-SW, além de N-S e E$\mathrm{W}$, gerando nesses setores os principais desnivelamentos topográficos observados na bacia (Figuras 7 e 8) e que exi- bem knickpoints, com rupturas que podem ser nitidamente visualizadas na figura 7 .

Todos os perfis longitudinais traçados a partir da orientação NW-SE, ou seja, dos canais afluentes e perpendiculares ao principal, apresentam rupturas nos respectivos perfis (Figura 7). Em alguns trechos exibem um traçado mais suavizado, com tendência à concavidade, marcados por significativas áreas de sedimentação, apontando condições de sorguimentos e abatimentos de blocos em concordância com as estruturas identificadas no embasamento.

Alguns estudos relacionam o desenvolvimento de knickpoints ao controle promovido por litologias diferenciadas ou à relação entre a orientação da foliação em relação aos fraturamentos (Dantas \& Coelho Netto, 1991; Silva et al., 1993; Dantas et al., 1994; Dantas, 1995) e mostram a importante atuação desses níveis de base locais na sedimentação das bacias de drenagem nos trechos à montante de tais feições e o encaixamento dos canais à jusante na bacia. De acordo com tais estudos, realizados no rio bananal, no Médio Vale do rio Paraíba do Sul, os vales apresentam-se estreitos e encaixados e com pouca sedimentação à jusante do nível de base local e, à montante, amplos e entulhados de sedimentos fluviais, geralmente interdigitados com feições de leques aluviais e colúvio, com as seções estranguladas nos fundos de vale. No caso das pesquisas citadas, tais condições estão associadas a dois fatores principais, um primeiro, ligado ao ângulo formado entre o bandamento/foliação principal (Sn) e a direção do segmento do canal, ou seja, quando a direção do canal é discordante em relação ao strike da foliação e, um segundo fator, associado à ocorrência de litologia diferencial, litologias mais resistentes que cruzam o eixo dos vales, sendo que o controle estrutural mais expressivo consiste na orientação do fraturamento em relação à foliação (Silva et al., 1993).

Na área foco deste artigo o comportamento dos canais é bem análogo ao descrito por estes autores, quando consideradas as morfologias geradas em associação com o desenvolvimento dos níveis de base locais. As comparações se anulam quando se observa a origem dos knickpoints já que, no caso da bacia do rio Bonito, a litologia é predominantemente homogênea e está vinculada à presença de estruturas que promoveram um escalonamento na bacia, principalmente por falhamentos com atitude normal com orientação NE-SW (Figura 2).

\subsubsection{Compartimento C4}

O compartimento C4 (Figura 2) corresponde a um importante alto topográfico na bacia, observado na área da fotografia (F) do perfil em varredura PV1 (Figura 8), com desnivelamento superior a 300 metros, delimitado por estru- 

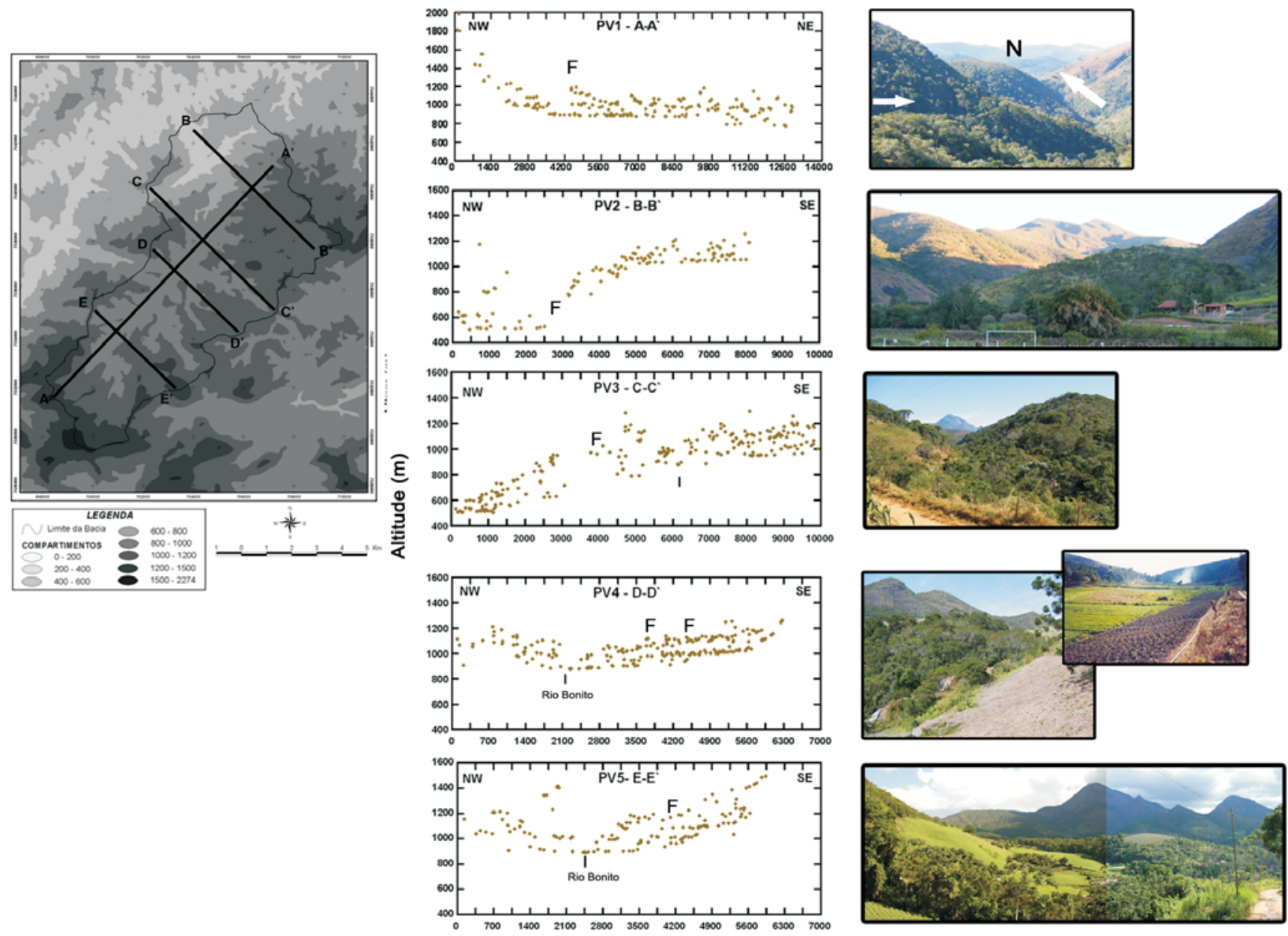

Distância (m)

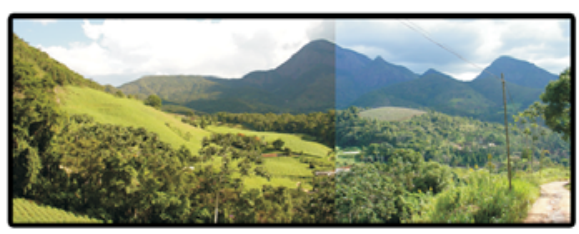

Figura 8 - Visualização dos perfis de relevo em varredura elaborados para as áreas traçadas no mapa hipsométrico e observação das fotografias das áreas indicadas nos perfis $(F)$.

turas E-W e NE-SW e SE-NW (Figuras 2 e 3), com atitude normal, que definem a orientação da rede de drenagem, também apontada na fotografia do PV1. A sedimentação nesse compartimento é menos expressiva indicando o predomínio de processos erosivos e com a área limite marcada por falhas, brechações e pacotes diferenciados de fluxos de movimentos rápidos.

É notável a abundante presença de anomalias da rede de drenagem (Figura 4), principalmente inflexões, curvas anômalas e cotovelos, que indicam uma complexa organização dos canais de drenagem, relacionada ao controle das estruturas subjacentes. Estruturas identificadas (Figura 2) nesse trecho indicam movimentação transcorrente dextral, visível no curso do canal, como pode ser observado na Figura 8, que segue formando um "S", o que é um indicativo de tal movimentação, como apontado por Sousa (2002). Estas estruturas ocorrem combinadas com estruturas orientadas NE-SW, NW$\mathrm{SE}$, além de N-S, que promovem truncamentos entre os diferentes lineamentos e, por sua vez, a geração de tais anomalias. Tais anomalias de drenagem e relevo vinculam-se a orientações discordantes às estruturas litológicas, assim como a morfologia normal das bacias.

\subsubsection{Compartimento C5}

O compartimento C5 (Figura 2) é limitado a sul por um importante lineamento com orientação NE-SW, no seu limite com o alto topográfico representado pelo compartimento C4. Lineamentos E-W limitam o compartimento e a bacia a sul (Figura 3). A direção do rio principal é distinta, seguindo orientação NW-SE, como visualizado na Figura 8. Os principais canais afluentes convergem para o canal principal seguindo o lineamento NE-SW, exibindo um retorno da imposição de 
estruturas NE-SW na orientação da rede de drenagem, já que no compartimento C4 apresenta uma orientação variada.

O rebaixamento do relevo nesse setor da bacia é expressivo, associado ao reverso do alto topográfico do compartimento $\mathrm{C} 4$, com desnivelamento topográfico da ordem de 300 metros, como se observa destacadamente no PL1 e PL2 da Figura 7 e no PV2 da Figura 8. Tal rebaixamento contribui para a formação de uma importante área de acúmulo sedimentar, associada ao nível de base do rio Preto, destacada no PV2 da Figura 8.

\section{Conclusão}

A evolução geomorfológica da área de estudos reflete o contexto geológico regional ao qual se insere. Os cinco compartimentos morfotectônicos identificados reproduzem a complexidade de feições observadas tanto no contexto local quanto regional.

Nesta pesquisa, mesmo que os dados estruturais tenham sido insuficientes para definir com mais clareza as paleotensões e assim definir melhor o(s) regime(s) tectônico(s) que viria(m) influenciar na estruturação da paisagem ao longo do cenozóico, ficou bastante clara a interferência direta das estruturas no relevo local. Os compartimentos exibem morfologias distintas que indicaram a influência mais efetiva no relevo local e na compartimentação morfotectônica das estruturas, sobretudo rúpteis, do que da litologia, visto ser a mesma predominantemente homogênea.

Dessa maneira, tendo como princípio que a tectônica influencia a evolução da paisagem, os dados obtidos mostram uma interferência direta das estruturas na dinâmica e evolução geomorfológica da área em estudo.

\section{Referências Bibliográficas}

Almeida, F.F.M. (1967) Origem e Evolução da Plataforma Brasileira. Rio de Janeiro, DNPM/DGM. (Boletim). $241 \mathrm{p}$.

Almeida, F.F.M. (1976) The system of continental rifts bordering the Santos Basin, Brazil. Anais da Academia Brasileira de Ciências, Rio de Janeiro, 48: 15-26.

Almeida, F.F.M. \& Carneiro, C.D.L. (1998) Origem e evolução da Serra do Mar. Revista Brasileira de Geociências, 28: 135-150.

Almeida, J.C.H. (2000) Zonas de cizalhamento dúctil de alto grau do Médio Vale do Rio Paraíba do Sul. Rio Claro (Tese de Doutorado-Geologia/UNESP), 201p.

Angelier, J. \& Mechler, P. (1977) Sur une méthode graphique de recherche dês contraintes principales également utilisable em tectonique et em seismologie: la méthode des diédres droit. Bulletin Societé Géologique de France, 19 (6): 1309-1318.

Arthaud, F. (1969) Méthode de determination graphique des directions de raccourcissement, d'allongment et intermédiaire d'une population de failles. Bulletin Societé Géologique de France, 11 (5): 729-737.

Assumpção, M. (1989) Seismicity and stresses in the Brazilian passive margim. Bulletin of Seismology Society of America, 88 (1): 160-169.

Borges, M.S.; Costa, J.B.S.; Hasui, Y.; Pires Neto, A.G.; Morales, N. \& Rueda, J.R.J. (1998) Compartimentação Neotectônica do Sudeste do Brasil. In: Congresso Brasileiro de Geologia, 40., Belo Horizonte. Anais... Belo Horizonte: Sociedade Brasileira de Geologia. p. 74.

Burbank, D.W. \& Anderson, R.S. (2001) Tectonic Geomorphology. Massachusetts: Blackwell Science. $274 \mathrm{p}$.

Carmo, I.O. (1996) Análise Estratigráfica de Depósitos Pleistocêncos no Médio Vale do Rio Paraíba do Sul. Rio de Janeiro (Dissertação de MestradoGeologia/UFRJ), 141 p.

Carmo, I.O. (2004) Geocronologia do Intemperismo Cenozóico no Sudeste do Brasil. Rio de Janeiro (Tese de Doutorado-Geologia/UFRJ), $134 \mathrm{p}$.

Costa, J.B.S; Borges, M.S; Hasui, Y.; Pires Neto, A.G. \& Morales, N. (1998) Bacias quaternárias do litoral norte do Estado de São Paulo. In: Congresso Brasileiro de Geologia, 40., Belo Horizonte. Anais... Belo Horizonte: Sociedade Brasileira de Geologia. p. 73.

Cox, R.T. (1994) Analysis of drainage-basin symmetry as a rapid technique to identify areas of possible Quaternary tilt.block tectonics: as example from the Mississipi Embayment. Geological Society of America Bullelin, 106: 571-581.

Cravinho, F.F.; Gontijo-Pascutti, A. H. F. \& Melo, P. B. (2003) Relevos tectônicos no Gráben do Rio Santana (RJ). In: Simpósio Nacional de Estudos Tectônicos, 9., Búzios. Anais... Rio de Janeiro: Sociedade Brasileira de Geologia - Núcleo RJ-ES. p.299-301.

Dantas, M.E. (1995) Controles naturais antropogênicos da estocagem diferencial de sedimentos fluviais: bacia do rio Bananal (SP/RJ), médio vale do rio Paraíba do Sul. Rio de Janeiro (Dissertação de Mestrado-Geografia/UFRJ, 142 p.

Dantas, M.E. \& Coelho Netto, A.L. (1991) Morfologia dos fundos de vale da bacia do rio Bananal (SP-RJ): 
médio vale do rio Paraíba do Sul. In: Simpósio de Geografia Física Aplicada, 4., Porto Alegre. Anais... Porto Alegre: UFRGS. p.113-120.

Dantas, M.E.; Eiraldo Silva, L.G. \& Coelho Netto, A.L. (1994) Spatially non-uniform sediment storage in fluvial systems: the role of bedrock knickpoint the Southeastern Brazilian Plateau. In: International Sedimentological Congress, 14., Recife. Proceedings..., IAS. J12-13.

Ferrari, A.L. (2001) Evolução tectônica do Gráben da Guanabara. São Paulo (Tese de DoutoradoGeologia/USP), 412 p.

Ferreira, M.F.M. (2001) Geomorfologia e análise morfotectônica do alto vale do Sapucaí - Pouso Alegre (MG). Rio Claro (Tese de DoutoradoGeologia/UNESP), 276 p.

Freitas, R.O. (1951a) Ensaio sobre a tectônica moderna do Brasil. Boletim da Faculdade de Filosofia, Ciências e Letras (série Geologia 6), 130: 120p.

Freitas, R.O. (1951b) Ensaio sobre o relevo tectônico do Brasil. Revista Brasileira de Geografia, 2: 171222.

Freitas, R.O. (1956) Considerações sobre a tectônica e geologia do Vale do Paraíba. Engenharia de Minas e Mealurgia, 24 (143): 276-284.

Gallagher, K.; Hawkesworth, C.J; Montovani, M.S.M. (1995) Denudation, fission track analysis and the longterm evolution of passive margin topography: application to the Southeast Brazilian margin. Journal of South American Earth Sciences, 8 (1): 65-77.

Gontijo, A.H.F. (1999) Morfotectônica do Médio Vale do Rio Paraíba do Sul: Região da Serra da Bocaina, Estados de São Paulo e Rio de Janeiro. Rio Claro (Tese de Doutorado-Geologia/UNESP), 259 p.

Gontijo, A.H.F.; Silva, T. M.; Moura, J. R. S. (2000) Anomalias de drenagem como elemento indicativo do controle neotectônico no Médio Vale do Rio Paraíba do Sul (SP/RJ) In: Simpósio Nacional de Geomorfologia, 3., Campinas. Anais... Campinas: UNICAMP, CD-ROOM.

Gontijo, A.H.F.; Borges, M.S.; Rueda, J.R.J.; Hasui, Y. \& Morales, N. (2002a) Perfis lateríticos bauxíticos e a fragmentação da Superfície Sul-Americana: um exemplo na Serra da Bocaina, estados de São Paulo e Rio de Janeiro. Geociências, 21 (1-2): 3-11.

Gontijo, A.H.F.; Melo, P.B.; Cravinho, F.F.; Moura, J.R.S.; Morales, N. \& Hasui, Y. (2002b) Morfotectonica e Geometria de Falhas no Gráben do Rio Santana-
RJ. In: Congresso Brasileiro de Geologia, 41., João Pessoa. Anais... João Pessoa: Sociedade Brasileira de Geologia. p.358.

Hackspacher, P.; Hadler, J.C., Lunes, J.P., Paulo, S.R., Ribeiro, L.F.B. \& Tello, C.A.S. (1999) Alguns dados sobre o período Cretáceo na serra da Mantiqueira através de Análise de Traços de Fissão em Apatitas (ATFA). In: Simpósio Sobre o Cretáceo no Brasil, 5., Serra Negra (SP). Rio Claro: UNESP, p. 33-37.

Hasui, Y.; Almeida, F.F.M.; Mioto, J.A. \& Melo, M.S. (1982) Geologia, tectônica, geomorfologia e sismologia regionais de interesse às usinas nucleares da praia de Itaorna. São Paulo: IPT. 149 p. (Monografia 7).

Hasui, Y. 1990. Neotectônica e Aspectos Fundamentais da Tectônica Ressurgente no Brasil. In: Workshop Sobre Neotectônica e Sedimentação Continental no Sudeste Brasileiro. Belo Horizonte: SBG (Núcleo MG). Boletim SBG/MG, 11: 11-31.

Hasui, Y. \& Costa, J.B.S. (1996) Neotectônica: fundamentos, métodos e técnicas de análise. In: Simpósio de Geologia da Amazônia, 5., Belém. Notas de Curso... Belém: SBG-Núcleo Norte, 20 p.

Hasui, Y.; Costa, J.B.S.; Borges, M.S.; Morales, N. \& Rueda, J.R.J. (1998) Evolução morfotectônica do Sudeste do Brasil. In: Congresso Brasileiro de Geologia, 40., Belo Horizonte. Anais... Belo Horizonte: SBG/ Minas Gerais. p. 78.

Heilbron, M.; Valeriano, C.M.; Tupinambá, M. \& Almeida, J.C.H. (1999) An evolutionary tectonic model for the central Ribeira Belt: from Transamazonian collage to Gondwana amalgamation. In: Simpósio Nacional de Estudos Tectonicos, 7., Lençois, Anais... SBG. p.58-61.

Heilbron, M.; Mohriak, W.; Valeriano, C.M.; Milani, E.; Almeida, J.C.H. \& Tupinambá, M. (2000) From collision to extension: the roots of the Southastern Continental Margin of Brasil. In: W. Mohriak \& M. Talwani (Eds). Atlantic Rifts and Continental Margins. 354 p. America Geophysical Union, Geophysical Monograph Series, 115: 1-34.

Hiruma, S.T.; Riccomini, C. \& Mondenesi-Gauttieri, M.C. (2001) Neotectônica no Planalto de Campos do Jordão, Revista Brasileira de Geociências, 31 (3): 375-384.

Keller, E.A.; Pinter, N. (eds) (1996) Active tectonics. Earthquakes, uplift and landscape. New Jersey: Prentice Hall, 338 p.

Liu, K.C. (1987) A geologia estrutural do Estado do Rio de Janeiro vista através de imagens do LANDSAT. 
In: Simpósio de Geologia RJ/ES, 1., Rio de Janeiro. Anais... Rio de Janeiro: SBG RJ/ES, p.164-188.

Mafra, N.M.C.; Lopes, M.R.S.; Sathler, R. \& Mendes, L.D. (1999) Caracterização física, química e mineralógica de solos de pedogênese diferenciada a partir de sedimentos aluviais, na Bacia do rio Bonito, Petrópolis, RJ. In: Simpósio Brasileiro de Geografia Física Aplicada, 7., Belo Horizonte. Anais... Belo Horizonte: UFMG, p.233 - 234.

Melo, M.S.; Riccomini, C.; Hasui, Y.; Almeida, F.F.M. \& Coimbra, M.C. (1985b) Geologia e evolução do sistema de bacias tafrogências continentais do sudeste do Brasil. Revista Brasileira de Geociências, 15(3): 193-201.

Melo, P.B.; Gontijo-Pascutti, A.H.F.; Cravinho, F.F. \& Moura, J.R.S. (2003) Orientações da rede de drenagem e sua relação com a tectônica mesozóico-cenozóica no gráben do Rio Santana, RJ. In: Simpósio Nacional de Estudos Tectônicos, 9., Búzios. Anais..., Rio de Janeiro: SBG-RJ, p. 302 - 304.

Mello, C.L. (1992) Fácies Sedimentares, Arquitetura Deposicional e Relações Morfoestratigráficas em um Sistema de Leques Aluviais Holocênicos: Aloformação Manso - Médio Vale do Rio Paraíba do Sul (SP/RJ). Rio de Janeiro (Dissertação de Mestrado-Geologia/UFRJ), 188p.

Mello, C.L.; Silva, T.M.; Moura, J.R.S. \& Hees, F.J. (1989) Evidências geomorfológicas e estratigráficas para um tectonismo recente na região de Bananal (SP). In: Simpósio de Geologia do Sudeste, 1., Rio de Janeiro. Anais... Rio de Janeiro: SBG (Núcleos SP e RJ), p. 26-27.

Mello, C.L.; Moura, J.R.S.; Carmos, I.O.; Silva, T.N. \& Peixoto, M.N.O. (1995) Eventos de sedimentação durante o Holoceno no médio vale do Rio Paraíba do Sul (SP/RJ) - aloestratigrafia e datações por radiocarbono. In: Congresso da Associação Brasileira de Estudos do Quaternário, 5. Anais... Niterói: ABEQUA, p. 193-197.

Mendes, L.D. (2001) Pedogênese diferenciada a partir de depósitos de gênese aluvial: bacia do rio Bonito, Petrópolis, RJ. Rio de Janeiro (MonografiaGeografia/UERJ), 100 p.

Mendes, L.D. (2004) Tectônica, rede de Drenagem e sedimentação no Planalto Serrano do Rio de Janeiro: o caso da bacia do rio Bonito (Petrópolis, RJ). Rio de Janeiro (Dissertação de MestradoGeografia/UFRJ), 130 p.

Mendes, L.D.; Mafra, N.M.C. \& Gontijo, A.H.F. (2002) Condições de desenvolvimento e caracterização de coberturas pedológicas a partir de depósitos aluviais em diferentes compartimentos morfotectônicos: Bacia do rio Bonito, Petrópolis, R.J. In: Simpósio Nacional de Geomorfologia, 4., São Luiz. Anais... São Luiz: UFMA, p. 64-64.

Morales, N. \& Hasui, Y. (2001) Neotectônica e compartimentação neotectônica da Região Sudeste e importância. Boletim da Sociedade Brasileira de Geologia, março/2001. p.4-5.

Neves, M.A. (1999) Evolução cenozóica da região de Jundiaí (SP). Rio Claro (Dissertação de MestradoGeologia/UNESP), 135 p.

Ollier, C.D. (1981) Tectonics and landforms. (Geomorphology texts). London: Longman Inc. 57-161.

Riccomini, C. (1989) O Rift Continental do Sudeste do Brasil. São Paulo (Tese de Doutorado-Geologia/USP), $256 \mathrm{p}$.

Riccomini, C.; Pellogia, A.U.G.; Saloni, J.C.L.; Kohnke, M.W. \& Figueira, R.M. (1989) Neotectonic activity in the Serra do Mar rift system (Southeastern Brazil). Journal of South American Earth Science, 2 (2): 191-197.

Ruellan, F. (1944) A evolução geomorfológica da Baía de Guanabara e das regiões vizinhas. Revista Brasileira de Geografia, 4(4): 445-508.

Saadi, A. (1990) Elementos de discussão da neotectônica brasileira. In: Semana de Estudos Geológicos, 31., Belo Horizonte, Anais..., 1-12.

Saadi, A. (1993) Neotectônica da Plataforma Brasileira: esboço e interpretação preliminar. Geonomos, 1(1): 1-15.

Saadi, A. \& Valadão, R.C. (1990) Eventos tectonosedimentares na bacia neo-cenozóica de Rio das Mortes (Região de São João del Rei-MG). In: Workshop Sobre Neotectônica e Sedimentação Cenozóica Continental no Sudeste Brasileiro, Belo Horizonte. Anais... Belo Horizonte: SBG (MG), 11: 81-99.

Salvador, E.D. \& Riccomini, C. (1995) Neotectônica da região do alto estrutural de Queluz (SP-RJ, Brasil). Revista Brasileira de Geociências, 25(3): 151-164.

Santos, M. (1999) Serra da Mantiqueira e Planalto do alto Rio Grande: a bacia terciária de Aiuruoca e evolução morfotectônica. Rio Claro (Tese de Doutorado-Geologia/UNESP), 134 p.

Schobbenhaus, C. \& Campos, D.A. (1984) A evolução da Plataforma Sul-Americana no Brasil e suas principais concentrações minerais. In: Schobbenhaus, C.; Campos, D.A.; Derze, G.R. \& 
Asmus, H.E. (coord.) Geologia do Brasil. Texto explicativo do Mapa Geológico do Brasil e da área oceânica adjacente incluindo depósitos minerais, Escala 1:2 500.000. Brasília: Departamento Nacional da Produção Mineral, p.9-53.

Silva, L.G.E.; Dantas, M.E. \& Coelho Neto, A.L. (1993) Condicionantes lito-estruturais na formação de níveis de base locais ("knickpoints") e implicações geomorfológicas no médio vale do rio Paraíba do Sul (RJ/SP). In: Simpósio de Geologia do Sudeste, 3., Rio de Janeiro. Atas... Rio de Janeiro: SBG, p.96102.

Silva, T.M. (2002) A estruturação geomorfológica do Planalto Atlântico no Estado do Rio de Janeiro. Rio de Janeiro (Tese de Doutorado- Geografia/ UFRJ), $264 \mathrm{p}$.
Sousa, M.O.L. (2002) Evolução tectônica dos altos estruturais de Pitanga, Ártemis, Pau d'Alho e Jibóia - centro do Estado de São Paulo. Rio Claro (Tese de Doutorado-Geologia/UNESP), 204 p.

Stewart, I.S. \& Hancock, P.L. (1994) Neotectonics. In: Hancock P.L. (ed.) Continental Deformation. Pergamon Press, 370-409.

Summerfield, M.A. (1987) Neotectonics and landform genesis. Progress in Physical Geology, 11: 384-397.

Thomas, D.S.G. \& Allison, R.J. (Eds.) (1993) Landscape Sensitivity. Chichester: John Wiley and Sons, 347 p.

Wallace, R.E. (Ed.) (1986) Active tectonics. National Academy Press. 266 p. 